\title{
AS BOAS PRÁTICAS DA INDÚSTRIA DO PETRÓLEO COMO O EIXO DA REGULAÇÃO DO SETOR
}

\author{
ALEXANDRE SANTOS DE ARAGÃO*
}

I- O Princípio da Legalidade e a Regulação da Indústria do Petróleo. II - O Poder de a ANP Elaborar e Celebrar Contratos de Concessão como Fatos Jus-Genéticos. III - A Função das Boas Práticas da Indústria do Petróleo.

\section{I - O princípio da legalidade e a regulação da indústria do petróleo}

Preliminarmente, devemos destacar que pouca divergência há quanto à necessidade de base legal para a Administração Pública editar os seus atos concretos, unilaterais e bilaterais, e normativos. As discussões se centram no nível de densidade normativa que essas leis devem possuir para outorgar poderes à Administração; ou seja, até que ponto a lei deve preestabelecer os conteúdos dos atos a serem expedidos infralegalmente pela Administração Pública; até que ponto pode conferir liberdade (sempre limitada) à Administração Pública para definir direitos e obrigações. Trata-se de identificar o âmbito em que a Administração Pública pode optar por tal ou qual medida, âmbito este de faculdade e poder que é reconhecido, querido e determinado pela lei.

CHARLES EISENMANN ${ }^{1}$ enumera quatro possíveis visões do Princípio da Legalidade, ou seja, quatro possíveis formas de se conceber a subordinação da Administração à lei. Vejamos, uma a uma, das menos para as mais restritivas dos poderes da Administração Pública:

* Professor das Pós-graduações em Direito do Estado da Universidade do Estado do Rio de Janeiro

- UERJ e em Direito da Administração Pública da Universidade Federal Fluminense - UFF.

Professor do Mestrado em Regulação e Concorrência da Universidade Candido Mendes. Membrofundador do Instituto Brasileiro de Estudos do Direito da Energia - IBDE. Membro do IAB e do IBAP. Procurador do Estado e Advogado no Rio de Janeiro (alexaragao@zipmail.com.br).

1 EISENMANN, Charles. Cours de Droit Administratif, Tomo I, Ed. L.G.D.J., Paris, 1982, pp. 462 a 472.

R. Dir. Adm.,

Rio de Janeiro, 238: 283-300,

Out./Dez. 2004 
1. Para a atuação da Administração Pública é suficiente que ela não viole qualquer norma legal, ou seja, na inexistência de normas legais que a obriguem a fazer ou a deixar de fazer algo, tem liberdade para atuar. Nesta acepção, a legalidade seria uma relação de não-contrariedade com a lei. ${ }^{2}$

2. A Administração Pública pode fazer o que uma norma superior, legal ou constitucional, a autorize, a habilite a fazer, ainda que não entre nos detalhes do conteúdo dos atos a serem emitidos. Nesta perspectiva, a Administração não possui liberdade na ausência de lei, mas basta que esta lhe atribua a competência. Privilegia-se, portanto, a existência de habilitação formal para o exercício de competência para a realização de determinados fins.

3. A Administração só pode emitir os atos que se esteiem em norma legal, não apenas habilitadora, mas predeterminante do conteúdo dos atos a serem praticados.

4. Em uma exigência adicional em face da visão anterior, a Administração Pública tem que estar apoiada em norma legal que esgote o conteúdo dos atos a serem tomados, a qual também deve determinar, e não apenas facultar, a sua prática. Por esta visão, todas as competências da Administração Pública só poderiam ser vinculadas.

A primeira visão é inviável por igualar a liberdade de atuação da Administração Pública àquela dos indivíduos, e, no choque entre estas duas liberdades, a esfera de autonomia dos indivíduos se veria, em razão da imperatividade dos atos da Administração Pública, reduzida a limites aquém daqueles que devem decorrer do Estado de Direito - que resguarda os indivíduos contra a vontade ilimitada das autoridades administrativas.

A quarta também seria impraticável, mas por razões opostas, já que impediria qualquer esfera de apreciação própria da Administração Pública em um Estado social de Direito, que possui múltiplas e complexas atribuições, a serem exercidas em um contexto de grande dinamismo.

A discussão fica, portanto, entre as duas opções intermediárias, que vêem o princípio da legalidade como impositivo de uma relação de conformidade da Administração Pública com a lei.

Pela terceira, a Administração Pública pretensamente não criaria direitos e obrigações, que já estariam previamente estabelecidos pela lei, mas apenas detalharia, ainda que com certa margem de discricionariedade, a maneira com deveriam ser implementados.

Pela segunda concepção, ao revés, bastaria a existência de leis autorizativas da atuação administrativa, que, sem chegar a pré-determinar o conteúdo dos direitos e

2 EISENMANN, Charles. O Direito Administrativo e o Princípio da Legalidade, in Revista de Direito Administrativo, vol. 56, pp. 54/5. 
obrigações, mas fixando alguns parâmetros, facultam à Administração Pública tomar uma entre várias medidas possíveis (ex.: "Tomar todas as medidas necessárias para alcançar os objetivos $x, y$ e $z ")$.

ODETE MEDAUAR, uma das poucas administrativistas brasileiras que tratam da doutrina de EISENMANN, essencial para a compreensão da matéria ora tratada, preleciona:

“ $O$ terceiro significado - somente são permitidos atos cujo conteúdo seja conforme a uma hipótese abstrata fixada explicitamente por norma legislativa -, traduz uma concepção rígida do princípio da legalidade e corresponde à idéia de Administração somente executora da lei; hoje não mais se pode conceber que a Administração tenha só este encargo. ${ }^{3}$ Esse significado do princípio da legalidade não predomina na maioria da atividade administrativa, embora no exercício do poder vinculado possa haver decisões similares a atos concretizadores de hipóteses normativas abstratas. ${ }^{4}$

O segundo significado exprime a exigência de que a Administração tenha habilitação legal para adotar atos e medidas; desse modo, a Administração poderá justificar cada uma de suas decisões por uma disposição legal; exige-se base legal no exercício dos seus poderes. Esta é a fórmula mais consentânea à maior parte das atividades da Administração brasileira, prevalecendo de modo geral. No entanto, o significado contém gradações; a habilitação legal, por vezes, é somente norma de competência, isto é, norma que atribui poderes para adotar determinadas medidas, ficando a autoridade

3 Em outra obra, a Professora ODETE MEDAUAR minudencia a sua posição: "Essa conotação decorre da idéia da Administração como executora da lei, que predominou no século XIX e princípios do século XX. Hoje essa idéia vem sendo questionada, ante as atribuiçōes atuais do Poder Executivo e da Administração e sobretudo porque a função administrativa talvez nunca tenha se limitado a executar a lei ou a executar a lei de ofício. Embora norteada pelo Princípio da Legalidade, a função administrativa não tem o fim único de executar a lei, desempenhando amplo rol de atividades que propiciam serviços, bens, utilidades, dificilmente 'enquadráveis' na rubrica 'execução da lei' " (MEDAUAR, Odete. A Processualidade no Direito Administrativo, Ed. RT, São Paulo, 1993, p. 53)

4 "A segurança jurídica da previsibilidade aplicativa das normas, permitindo almejar como ideal de sistema administrativo uma postura decisória siolgístico-subsuntiva das normas, encontra-se hoje completamente ultrapassada pela flexibilidade do conteúdo da legalidade". (...) Em vez disso, assiste-se a uma progressiva indeterminação e abertura densificadora da normatividade a favor da Administração Pública que, por sua esta via, adquire um crescente ativismo na revelação $e$ construção das soluçōes concretas e regulamentares, conferindo-se uma inerente maleabilidade à legalidade administrativa que vive tempos de erosão do seu habitual e repetido papel puramente vinculativo da atuação administrativa. (...) Os alicerces politicos do princípio da legalidade administrativa revelam que, ao invés da interpretação tradicional dos postulados filosóficos liberais, a vontade do poder executivo nunca é totalmente alheia ao conteúdo configurativo dessa mesma legalidade: a idéia de uma genérica natureza heterovinculativa da legalidade face ao poder executivo é um mito" (OTERO, Paulo. Legalidade e Administração Pública - o sentido da vinculação administrativa à juridicidade, Ed. Almedina, Coimbra, 2003, pp. 162, 894 e 1.101). 
com certa margem de escolha no tocante à substância da medida; por vezes, a base legal expressa um vínculo estrito do conteúdo do ato ao conteúdo da norma ou às hipóteses aí arroladas." 5

Tomando por paradigma as quatro possíveis concepções da legalidade colacionadas por EINSENMANN, podemos afirmar que GUIDO ZANOBINI ${ }^{6}$ critica a visão de que a Administração Pública constitui um poder apenas "executivo", já que a ela não compete simplesmente "executar e implementar a norma jurídica, mas sim, o que é profundamente diverso, satisfazer os interesses coletivos". '

JOSÉ MANUEL SÉRVULO CORREIA ${ }^{8}$ deduz da distinção de CHARLES EISENMANN as seguintes concepções do Princípio da Legalidade: (a) não-contrariedade (compatibilidade, preferência da lei ou legalidade-limite), ou seja, a exigência de a ação administrativa não poder entrar em contradição com uma lei, apesar de não necessariamente haver de nela ter um esteio; e (b) conformidade (reserva de lei ou legalidade-fundamento), que, além da não-contradição, exige que a Administração atue com respaldo em alguma lei, de forma que os seus atos sempre consistam de alguma forma na aplicação de preceitos legais (ou, naturalmente, constitucionais).

Essa "conformidade", todavia, subdivide-se, podendo reduzir-se à (b.l) mera legalidade formal, pela qual "basta a existência de normas que tenham por objectivo regular a produção jurídica do acto, atribuindo poderes para a sua emissão", 9 não

5 MEDAlAR, Odete. Direito Administrativo Moderno, Ed. RT. $7^{\mathbf{a}}$ edição, São Paulo, 2003, p. 137.

6 ZANOBINI, Guido. L'Attività Amministrativa e la Legge, in Scritti Vari di Diritto Pubblico, Ed. Giuffrè, Milano, 1955, pp. 203 a 218.

7 "Para Hegel, a função do Monarca na aplicação da lei seria somente a de por o pingo no 'i'. Todavia, em todos os filósofos não se contesta a questão de como se deve preencher o abismo entre a lei necessariamente geral, que deve 'dominar', e as necessárias decisões nas situações concretas. Não se pode desconhecer que se trata de algo mais do que uma simples aplicação da lei. Trata-se do estabelecimento de normas sob o Direito Constitucional e de atos relacionados com uma situação concreta. Ambas coisas exigem que sejam adotadas decisões obrigatórias para outros. Assim, com a simples fórmula de que não devem ser os homens que dominam, mas sim as leis abstratas e impessoais, não se resolveu nada" (LARENZ, Karl. Derecho Justo, trad. Luis Diez-Picazo, Ed. Civitas, Madrid, 1985, pp. 153/4). Vê-se, assim, o caráter meramente mítico de uma estrita vinculação da Administração Pública à lei.

8 CORREIA, José Manuel Sérvulo. Legalidade e Autonomia Contratual nos Contratos Administrativos, Livraria Almedina, Coimbra, 1987, pp. 58-63 e 309-312.

9 CORREIA, José Manuel Sérvulo. Legalidade e Autonomia Contratual nos Contratos Administrativos, Livraria Almedina, Coimbra, 1987, pp. 58 a 60. Também analisando a nomenclatura de CHARLES EISENMANN, JUAN IGARTUA SALAVERRÍA observa que a compatibilidade e a conformidade são distintas porque o significado desta é o de deduzibilidade (não apenas compatibilidade) da lei (SALAVERRÍA, Juan Igartua. Princípio de Legalidad, Conceptos Indeterminados y Discrecionalidad Administrativa, in Revista Española de Derecho Administrativo - REDA, 1996. vol. 92, versão $C D-R O M$ ). Todavia, segundo o autor, esta deduzibilidade poderia advir de dois momentos argumentativos diferentes: com a lei prevendo a hipótese de incidência e a consequiência jurídica que deve se seguir à sua realização concreta; ou com a lei prevendo fins e meios para alcançá-los (silogismo prático). 
sendo necessária a (b.2) legalidade material, por força da qual a lei já deve pré-determinar parte ou todo o conteúdo dos atos a serem praticados pela Administração Pública. ${ }^{10}$

Partindo-se da Pirâmide Normativa e da Teoria Gradualista de KELSEN, constatamos, por um lado, que todo ato da Administração Pública está apoiado em um ato superior - geralmente uma lei —, mas também que, por outro lado, "toda concreção de normas gerais, toda passagem de um grau superior para um grau inferior da ordem jurídica, implica preencher um vazio, respeitando os limites traçados pelas normas de grau superior. Como a concreção das disposições inferiores nunca pode ser completamente prevista pela norma superior, existe um espaço criativo, que, conforme a postura kelseniana, pode e deve ser integrado não só pelo administrador público, como também pelo juiz. Considera que ambas as funções não estão completamente determinadas pela legislação, já que existe uma margem mais ou menos ampla de apreciação, mas esta liberdade não é nunca absoluta e, ao contrário, sempre pressupõe uma norma prévia". ${ }^{11}$

Não seria suficiente, contudo, apenas a previsão legal da competência da Administração Pública editar normas sobre determinado assunto. Mister se faz que a lei estabeleça também princípios, finalidades, políticas públicas ou standards ${ }^{12}$ que propiciem o controle do regulamento (intelligible principles doctrine), já que a atribuição de poder normativo, sem que se estabeleçam alguns parâmetros para 0 seu exercício, não se coadunaria com o Estado Democrático de Direito, que pressupõe a possibilidade de controle de todos os atos estatais.

10 CORREIA, José Manuel Sérvulo. Legalidade e Autonomia Contratual nos Contratos Administrativos, Livraria Almedina, Coimbra, 1987, pp. 58 a 60. Entre nós, ver GUIMARÃES, Fernando Vernalha. Alteração Unilateral do Contrato Administrativo, Ed. Malheiros, São Paulo, 2003, p. 250.

11 SESÍn, Domingo J. Administración Pública. Actividad Reglada, Discrecional e Técnica, Ed. Depalma, Buenos Aires, 1994, pp. 04 e 05, grifamos. Assim, demonstrada fica a inviabilidade de se adotar uma visão rígida da legalidade, pela qual a Administração Pública só poderia fazer aquilo que a lei previamente a autorize, em outras palavras, não há como a lei pré-determinar todos os elementos dos atos administrativos, o que, na prática, nunca foi na prática possível ao Legislador. 12 "O standard jurídico constitui uma maneira de solução de conflitos de interesses na qual o aplicador da lei adota diretivas como normas de conduta, que lhe permitem resolver o caso com sentido de justiça considerando os fatores econômicos, sociais e até mesmo morais existentes dentro da norma legal e de princípios de aplicação flexível. Há nele uma boa dose de empirismo e pragmatismo. A eqüidade quase sempre está neste tipo de decisão, e a eficiência será maior quanto maior for a flexibilidade institucional" (BIELSA, Rafael. Metodologia Juridica, Libreria y Editorial Castellví, Santa Fé, 1961, pp. 509 e 510). Como observa FRANCESCO MANGANARO, "não se trata de desvalorizar o papel da lei, mas de reconsiderar a sua função em um ordenamento pluralista. Se a rápida evolução social já era um motivo para preferir uma legislação farta de princípios e standards, por mais fortes razões, um ordenamento em que há um efetivo pluralismo requer uma formulação legislativa de tal gênero (MANGANARO, Francesco. Principio di Legalità e Semplificazione dell'Attività Amministrativa: i profili critici e principi ricostruttivi, Edizioni Scientifiche Italiane, Napoli, 2000, p. 171). 
Note-se que nos Estados Unidos da América do Norte, onde também havia forte setor doutrinário e jurisprudencial no sentido de que as leis com tal (baixa) densidade normativa seriam inconstitucionais por constituírem delegações de poderes legislativos, a Suprema Corte acabou se firmando, como expõe JOHN H. REESE, no sentido de que "o que é proibido é a transferência de poderes ilimitados. Normalmente, tal transferência limitada advém da linguagem utilizada na lei autorizando a Administração a editar normas apropriadas para cumprir as finalidades assinaladas na lei. A transferência de poderes normativos também pode estar implícita na linguagem legislativa, ainda que não haja atribuição normativa expressa". ${ }^{13}$

Recentemente, a Suprema Corte teve a oportunidade de reafirmar a sua posição no caso Whitman v. American Trucking Associations Inc., em que, apesar da posição adotada pelo Tribunal Federal ad quem pela inconstitucionalidade da lei atributiva de largos poderes normativos a agência administrativa, considerou constitucional disposição legal que atribuiu poder normativo para "estabelecer padrões de qualidade do ar, cuja observância seja necessária para proteger a saúde pública”.

Também na Itália se exige que a lei atributiva do poder regulamentar contenha os respectivos "princípios e critérios diretivos"; 14 ao passo que na Alemanha "o Tribunal Constitucional Federal, conjuntamente com a doutrina, criou a figura da Bestimmheitsgebot, ou seja, a exigência de uma determinabilidade, que a lei autorizativa do poder regulamentar deve satisfazer para evitar leis excessivamente genéricas ou que transfiram ao Executivo uma competência normativa sem limites do ponto de vista finalístico (uma "carta-branca"), sendo que, atualmente, a doutrina é cada vez mais propensa a entender suficiente que o 'escopo' possa ser inferido também da interpretação do contexto jurídico no qual a lei de autorização é emanada". ${ }^{15}$

Sob o mesmo prisma, se afirma também na doutrina nacional que, o que não pode ocorrer, é "a disciplina normativa produzida pela lei ser tão sumária que sua complementação possa conduzir a um resultado qualquer. Preocupada com a proliferação de leis de baixíssima densidade normativa, a doutrina construiu o conceito de conteúdo essencial (contenu essentiel, wesentlichkeitstheorie). Tais leis devem

13 REESE, John H. Administrative Law - Principles and Practice, Westpublishing Co., Saint Paul, Minnesota, 1995, p. 53, grifo do autor. WILLIAM F. FUNK explica: "o Congresso legisla e a Administração executa as leis; para que a Administração execute as leis, estas leis devem conter um princípio claro (intelligible principle) para guiar a Administração, já que, do contrário, a Administração estaria legislando por conta própria" (FUNK, William F. Administrative Practice \& Procedure, 2^ edição, West Group, 2001, p. 522).

14 ROMANO, Alberto. Relazione di Sintesi, in Amministrazione e Legalità - Fonti Normativi e Ordinamenti (Atti del Convegno, Macerata, 21 e 22 maggio 1999), Giuffrè Editore, Milano, 2000. p. 105.

15 ROMANO, Maria Chiara. Principio di Legalità e Regolamenti in Germania, in Amministrazione e Legalità - Fonti Normativi e Ordinamenti (Atti del Convegno, Macerata, 21 e 22 maggio 1999), Giuffrè Editore, Milano, 2000, p. 226. 
expressar, na lição de GARCÍA DE ENTERRÍA, 'uma diretiva legislativa precisa, sem supor uma cessão formal ou em branco de poder normativo'." 16

No mesmo sentido propugnado, o Superior Tribunal de Justiça - STJ ${ }^{17}$, lavrou acórdão no qual o MINISTRO HUMBERTO GOMES DE BARROS afirmou a possibilidade da Administração Pública, para alcançar as finalidades genéricas da disciplina da matéria, mas sem qualquer autorização legal específica, restringir a liberdade dos "postos de gasolina" adquirirem combustiveis aos de sua bandeira. A importância do acórdão é que é um dos poucos exemplos em que a nossa jurisprudência foi além de questões atinentes ao caso concreto, tratando do âmago doutrinário e teórico da matéria, ou seja, do que deve ser entendido como "execução de lei". Vejamos:

"A Constituição Federal, em seu art. 170, preceitua que a ordem econômica é fundada na valorização do trabalho humano e na livre iniciativa, tendo por finalidade assegurar a todos a existência digna, conforme os princípios que enuncia. No seu art. 174 pontifica que, como agente normativo, e regulador da atividade econômica, o Estado exercerá, na forma da lei, as funções de fiscalização, incentivo e planejamento. Desses dispositivos resulta claro que o estado pode atuar como agente regulador das atividades econômicas em geral, sobretudo das que cuidam as empresas que atuam em um setor absolutamente estratégico, daí lhe ser lícito estipular preços que devem ser por elas praticados. Montado nestes argumentos, não tenho dúvida em afirmar que o senhor Ministro dispõe de autoridade para impedir que o granelista venda combustível ao varejista ligado a bandeira que não é a sua. Como registrei acima, controlar a execução de determinada norma é fazer com que ela se desenvolva em busca dos fins sociais para a qual a regra foi concebida. Os preceitos que disciplinam a distribuição de combustíveis têm como finalidade fazer com que os usuários de tais produtos recebam, com segurança e facilidade, produtos de boa qualidade. Isto ocorre, porque, a exibição do logotipo de marca famosa traduz a afirmação de que no local se vende daquela marca. Ora, se o posto negocia produtos cuja origem não corresponda à sua bandeira, ele estará enganando o freguês (...). Quando o freguês é iludido, a distribuição de combustível não estará correspondendo aos fins sociais que orientam as normas disciplinadoras da distribuição de combustíveis".

O Supremo Tribunal Federal - STF em diversas ocasiões também já fixou a legitimidade da atribuição de poder normativo através de standards e finalidades genéricas estabelecidas em lei. Em recente decisão liminar em Ação Direta de Inconstitucionalidade (ADIN $n^{\circ}$ 1.668/DF, Relator MINISTRO MARCO AURÉ-

16 PESSOA, Robertônio Santos. Administração e Regulação, Ed. Forense, Rio de Janeiro, 2003, p. 145.

17 MS 4.578/DF (grifos nossos). 
LIO), o STF considerou constitucional a habilitação normativa efetuada pelos incisos IV e X do art. 19 da Lei Geral de Telecomunicações - LGT em favor da ANATEL, desde que ela se subordine aos preceitos legais e regulamentares pertinentes.

No Recurso Extraordinário $n^{\circ} 76.629 / R S$, o MINISTRO ALIOMAR BALEEEIRO afirmou que "se o legislador quer os fins, concede os meios. (...) Se a L. 4.862 expressamente autorizasse o regulamento a estabelecer condições outras, além das que ela estatuir, aí não seria delegação proibida de atribuições, mas flexibilidade na fixaçāo de standards jurídicos de caráter técnico, a que se refere Stati" (grifamos)..$^{18}$

Ainda é necessário distinguir a distinção da intensidade da incidência do Princípio da Legalidade conforme: (a) a atividade da Administração Pública restrinja direitos ou crie obrigações para particulares ou, ao revés, (b) não tenha esta natureza ablativa, mas sim, muitas vezes, até mesmo concessiva de direitos, como nos casos em que outorga aos particulares o exercício de direitos que não integravam originariamente a esfera privada, a exemplo das concessões petrolíferas. ${ }^{19}$

Nesse sentido, LUÍS ROBERTO BARROSO, após distinguir a reserva de lei (ou precedência de lei, pela qual todos os atos administrativos devem se fundar em uma lei anterior) da preeminência de lei (ou prevalência de lei, pela qual a lei tem preferência sobre os atos administrativos, mas não precisam a eles pré-existir), afirma que "no Direito brasileiro, o princípio da legalidade, genericamente considerado, significa reserva de lei no que toca à criação de deveres e obrigações e uma mera preeminência de lei nos demais domínios das relações públicas e privadas." 20

A Lei do Petróleo, portanto, com as características das leis contemporâneas, sem dar início de per se a uma normatização mais completa, e, muito menos,

18 "É preferível uma legislação de princípios gerais e standards, do que uma legislação feita de regras, cujos conteúdos tendem a ficar obsoletos em um lapso de tempo sempre cada vez mais breve. Em outras palavras, é difícil colocar dentro de normas de conteúdo determinado uma realidade social em contínua evolução. (...) Se sabe que um excesso de regras é o melhor modo de deixar a Administração de se subtrair à sua observância, já que a burocracia, diante de muitas regras, acaba ficando substancialmente livre para aplicar a interpretação que considere mais adequada ao caso concreto. Uma desregulamentação da atividade administrativa não serve para resolver o problema, quando o que se deve é reconsiderar o papel da norma (e do jurista) em um ordenamento em contínua evolução. A consequiência imprescindível é a necessidade de 'uma revisão do papel constitucional da Administração e do próprio Princípio da legalidade’, que a doutrina é chamada a elaborar, em um momento em que já está em fase avançada a transição normativa para uma Administração por objetivos, que exalta o papel da eficiência da ação administrativa" (MANGANARO, Francesco. Principio di Legalità e Semplificazione dell 'Attività Amministrativa: $i$ profili critici e principi ricostruttivi. Edizioni Scientifiche Italiane, Napoli, 2000, p. 165).

19 Quer se queira admitir, quer não, em abstrato, eficácia jurídica constitutiva ao poder da Administração, não se pode negar que há alterações para mais quando celebra contratos administrativos com os privados. Antes e depois do contrato o mundo jurídico foi, pela Administração, de algum modo, modificado.

20 BARROSO, Luís Roberto. Apontamentos sobre o Princípio da Legalidade (Delegações legislativas, poder regulamentar e repartição constitucional das competências legislativas), in Temas de Direito Constitucional, Ed. Renovar, Rio de Janeiro, 2001, p. 169. 
exaustiva da matéria, estabelece parâmetros e objetivos gerais da regulamentação a ser feita pela ANP, que deverá buscar "preservar o interesse nacional" (art. $1^{\circ}, \mathrm{I}$ ), "valorizar os recursos energéticos" (art. $1^{\circ}$, II), "promover a livre concorrência" (art. $1^{\circ}$, IX), "atrair investimentos" (art. $1^{\circ}, \mathrm{X}$ ), "ampliar a competitividade do país" (art. $1^{\circ}, \mathrm{XI}$ ), "promover o aproveitamento racional dos recursos energéticos do País" (art. $\left.2^{\circ}, \mathrm{I}\right)$, " assegurar o suprimento de insumos energéticos" (arts. $2^{\circ}, \mathrm{II}$, e $8^{\circ}, \mathrm{I}$ ), proteger "os interesses dos consumidores" (art. $8^{\circ}, \mathrm{I}$, in fine), atender "às melhores práticas da indústria internacional do petróleo" (art. 44, VI), etc.

A Lei do Petróleo, portanto, a exemplo das demais leis instituidoras de agências reguladoras, integra a categoria das leis-quadro (lois-cadre) ou standartizadas, próprias das matérias de particular complexidade técnica e dos setores suscetíveis a constantes mudanças econômicas e tecnológicas.

As leis com estas características não dão maiores elementos pelos quais o administrador deva pautar a sua atuação, conferindo à Administração Pública um grande poder de integração do conteúdo da vontade do Legislador, dentro dos quadros por ele estabelecidos. O objetivo das leis assim formuladas é "introduzir uma vagueza que permita o trato de fenômenos sociais, muito fugazes para se prestarem ao aprisionamento em uma regra precisa." 21

Vemos, assim, que a Agência Nacional do Petróleo - ANP possui amplo poder para criar cláusulas dos contratos de concessão e dos respectivos editais de licitação, tanto pela atribuição desse poder pela Lei do Petróleo, que concomitantemente estabelece os princípios a serem seguidos neste mister (legalidade como conformidade material), como porque, nessa atividade, a Agência não está limitando a esfera jurídica dos particulares, mas, ao revés, a está ampliando (legalidade como preeminência de lei), considerando que, com a concessão, o particular passa a ter direitos dos quais não era titular apenas por força da sua livre iniciativa, ou seja, são direitos que se encontravam fora do comércio.

Sob os paradigmas teóricos acima expostos, podemos, seja em relação às suas potencialidades, seja no que toca aos seus limites, emitir as seguintes assertivas quanto à possibilidade de a Agência Nacional do Petróleo - ANP, com base na Lei do Petróleo, estabelecer normas contratuais. Vejamos: ${ }^{22}$

1. A ANP deve, ao elaborar editais de licitação e contratos de concessão para a exploração e produção de petróleo, atender aos objetivos cuja realização lhe é atribuída pela Lei do Petróleo e pelo Conselho Nacional de Política Energética (arts. $1^{\circ}, 2^{\circ}$ e $8^{\circ}$, Inciso 1 , da Lei do Petróleo). Ao estabelecer estas normas editalícias e contratuais, a ANP estará sempre sujeita às normas constitucionais, legais e regulamentares pertinentes.

21 Danièle Bourcier, La Décision Artificielle, PUF, 1995, p. 61. Maurice Hauriou destaca a grande importância desta técnica legislativa no Direito Administrativo, vez que "o standard, flexível e mutável, representa no direito o elemento de mobilidade" (Aux Sources du Droit, Librarie Bloud \& Gay, Paris, 1993, pp. 150/1, grifamos).

22 Cf. ARAGÃO, Alexandre Santos de. As Concessões e Autorizações Petrolíferas e o Poder Normativo da ANP, in Revista de Direito Administrativo - RDA, vol., vol. 228. 
2. Na determinação dos meios para a realização dos fins da Lei do Petróleo e da Política Nacional do setor (ex.: art. $8^{\circ}$, incisos I, IX e X), a Agência possui, via de regra, ampla margem de discricionariedade, não só para a emissão de normas gerais e abstratas, como para a fixação das cláusulas dos contratos de concessão e dos termos das autorizações. A margem de normatização da Agência é, no entanto, menor nos casos em que a própria Lei houver pré-determinado os meios (leia-se, as normas e cláusulas) das quais deverá se valer para atendimento dos objetivos nela fixados.

3. Muitas vezes a própria Lei expressamente remete a matéria à regulamentação da ANP (ex.: arts. $8^{\circ}, \mathrm{III}, \mathrm{V}$, in fine, VI, XV; $9^{\circ} ; 29$, in fine; $53, \S 1^{\circ}$; 56 , parágrafo único). Todavia, como visto na decisão do STJ acima citada, o fato da Lei remeter expressamente determinadas matérias às normas da Agência, não elide os amplos poderes normativos que via de regra existem em matérias não especificadas e não exaustivamente disciplinadas pela Lei.

Condensando o exposto neste Tópico, podemos afirmar que o poder de a Agência Nacional do Petróleo - ANP fixar as cláusulas dos contratos de concessão deverá, malgrado a sua inegável amplitude, se basear nos princípios do Estado Democrático de Direito e da Administração Pública, notadamente nos princípios da proporcionalidade/razoabilidade e da eficiêncialeconomicidade, restringindo os direitos e interesses dos particulares ou deixando de reconhecê-los, apenas na medida em que a restrição for o meio menos oneroso capaz de atingir com eficiência os fins públicos legitimamente almejados.

\section{II - O poder de a anp elaborar e celebrar contratos de concessão como fatos jus-genéticos}

Colocado o amplo poder conferido pela Lei do Petróleo à ANP para elaborar os seus contratos de concessão, podemos afirmar que, ressalvados os casos em que a própria lei pré-estabelecer determinada cláusula ou em que houver inegável contradição com os princípios nela estabelecidos ${ }^{23}$, a Agência possui autonomia contratual para criar cláusulas contratuais, seja nos espaços não pré-normatizados pela lei, seja na sua integração ou interpretação. ${ }^{24}$

23 Ou seja, em que estiver além de qualquer margem razoável de discricionariedade.

24 Mesmo se prescindindo dos concretos pressupostos filosóficos de Kelsen, para quem a autonomia é delegação de poder com apoio último na norma fundamental em sentido lógico-transcendental, outros autores chegaram à mesma solução. Emilio Betti, por exemplo, forte crítico do mestre de Viena, elaborou perspectiva que ficou conhecida como teoria da recepção, mediante a qual se vê, no ato de autonomia, a entrada da vontade para compor o pressuposto da norma, a qual admite e quer a presença de um sujeito atuante e gerador de regras para funcionamento harmônio do próprio sistema jurídico. Afirma o autor que: “'autonomia' significa, em geral, atividade e poder de se atribuir um ordenamento, de dar assim assento às próprias relações e interesses, desenvolvidas a 
Com efeito, a integração/complementação e a interpretação da Lei do Petróleo devem, com base nos seus princípios, ser feitas primordialmente pela ANP, assegurado o controle pelo Poder Judiciário e pelo Tribunal de Contas apenas nas hipóteses em que a decisão tomada for, fora de qualquer dúvida hermenêutica, irrazoável, ou seja, quando se encontrar em uma zona de certeza negativa (não meramente nebulosa, em que duas ou mais interpretações poderiam ser igualmente consideradas razoáveis) de cumprimento da Lei.

Vemos, destarte, que, observada a Lei, a ANP possui competência para celebrar contratos enquanto fatos jurígenos autonomamente considerados, isto é, as cláusulas de tais contratos são aptas a criar obrigações e direitos para os particulares (principalmente direitos, em que, como visto, as peias do Princípio da legalidade são bem menos rígidas, bastando, para alguns autores, a mera não-contradição com a Lei) de per se, não como mera execução subsuntiva de dispositivos legais.

À ANP possui foi conferido amplo poder criativo de, interpretando e integrando a Lei, desenvolver os seus objetivos maiores, muito além de estar apenas executando determinado inciso ou alínea legal. Seria, de fato, uma visão muito mesquinha e minimalista dos poderes da ANP elaborar os seus contratos de concessão, achar que todas as cláusulas desses estariam adredemente previstas na Lei do Petróleo.

O contrato é fonte originária de obrigações e direitos do particular e de poderes e de sujeições da Administração Pública, integrando os editais de licitação e os contratos de concessão de per se o marco regulatório da Indústria do Petróleo.

As leis não são as únicas fontes imediatas de direitos e obrigações. O ordenamento jurídico deixa espaço livre de autonomia para os sujeitos jurídicos estabelecerem voluntariamente vínculos entre si, com obrigações oriundas, não da lei, mas do acordo de vontades. ${ }^{25}$

partir do próprio ente ou sujeito a que dizem respeito" (BETTI, Emilio. Autonomia Privata in Novissimo Digesto Italiano, t. I, Torino, UTET, p. 1.559).

${ }_{25}$ "Todas as vezes que as regras jurídicas aludem a suportes fáticos, em que a vontade seja um dos elementos, admitem elas que esses suportes fáticos se componham ou não se componham. Dizem, também, até onde se pode querer. Portanto, supōe-se que alguém queira ou não-queira. $\mathrm{O}$ auto-regramento, a chamada "autonomia da vontade", não é mais do que isso. A vida social tece-se com interesses, em relações inter-humanas, que necessariamente ultrapassam e ficam aquém da esfera jurídica, isto é, da zona colorida em que a) os fatos se fazem jurídicos, b) relações nascidas independentemente do direito se tornam jurídicas, e c) relaçōes jurídicas, nascidas, portanto no direito, se estabelecem. Vive-se em ambiente de contínua iniciativa particular, privada, ou em movimentos grupais, de multidão ou de massa. Os sistemas jurídicos apenas põem no seu mundo, dito mundo jurídico, parte dessa atividade humana. Ainda assim, não a prendem de todo e deixam campo de ação, em que a relevância jurídica não implique disciplinação rígida da vida em comum. Já aqui se pode caracterizar o que se passa, em verdade, com os atos humanos interiores ao campo de atividade, a que se chama auto-regramento da vontade, 'autonomia privada', ou 'autonomia da vontade': é o espaço deixado às vontades, sem se repelirem do jurídico tais vontades. Enquanto, a respeito de outras matérias, o espaço deixado à vontade fica por fora do direito, sem relevância para o direito; aqui, o espaço que se deixa à vontade é relevante para o direito. É interior, portanto, às linhas traçadas pelas regras jurídicas cogentes, como espaço em branco cercado pelas regras que o limitam" (PONTES DE MIRANDA, Francisco Cavalcanti. Tratado de Direito Privado, t. III, Rio de Janeiro, Borsoi, 1954, pp. 54-55). 
Ora, não parece adequado sustentar que esta faculdade negocial jus-genética deixe de existir tout court quando uma das partes for o Estado. Em primeiro lugar, como a concessão pressupõe a adesão voluntária do privado, não há invasão da esfera jurídica individual; e em segundo lugar, em sendo assim, não há razão para se retirar do Estado o acordo de vontades como um instrumento que, a par da lei, também se presta à realização dos interesses públicos, caracterizando-se, assim, "o contrato de concessão como uma espécie de fonte de legalidade administrativa 'inter partes"' 26. "O acordo de vontades como criador de regras jurídico-administrativas faz do sujeito ordinário parte ativa da definição e realização do interesse público cria em primeiro plano verdadeiras relações jurídicas - inclusive de longa duração - baseadas naquelas regras." 27

O Princípio da Legalidade, mesmo em sua acepção mais rígida, foi elaborado para assegurar a esfera jurídica dos particulares diante de atos imperativos que gerem gravames, não para aqueles que beneficiem o particular ou que se expressem em convenções, até porque, lembremos, tanto a lei, como o contrato, podem ser fontes de direito. ${ }^{28}$

PAULO OTERO, em sua notável, pelo tamanho e pela qualidade, obra sobre o Princípio da Legalidade alude à "vinculação bilateral" da Administração Pública, de maneira que "pela via contratual podem surgir verdadeiras regras gerais reguladoras ou disciplinadoras de situações jurídicas presentes ou futuras envolvendo a Administração Pública". ${ }^{29}$

Prosseguindo na argumentação, o autor demonstra que os contratos e editais, especialmente de concessão, são capazes de gerar direitos e obrigações: "nestas situações existe um considerável domínio de autonomia de estipulação do conteúdo dos contratos da Administração Pública que, dentro dos limites da lei, se mostra passível de integrar o bloco de legalidade". ${ }^{30}$

26 VALDEZ, Oscar Aguilar. El Acto Administrativo Regulatorio, in Acto Administrativo y Reglamento, Ediciones RAP, Buenos Aires, 2002, p. 457, grifamos.

27 ALFONSO, Luciano Parejo. Los Actos Administrativos Consensuales, in Revista de Direito Administrativo e Constitucional $-A \& C$, vol. 13, p. 15. MARÍA MERCEDES MALDONADO COPELLO vê "o contrato", sobretudo nas concessões latino americanas a partir da década de oitenta, "como o mecanismo por excelência de regulação" (COPELLO, María Mercedes Maldonado. Privatización de los Servicios Públicos Domiciliarios y Transformación del Derecho Estatal en Colombia, in Anuário 2001 GEDIM - Dez Anos de Mercosul, Ed. Lumen Juris, Rio de Janeiro, p. 329).

28 Nestes sentido é relevante inclusive notar que doutrina autorizada conceitua as concessões de serviços públicos como "atos-condição, ou melhor, como acordos-condição, cujo efeito não é o de criar uma regulamentação, mas de desencadear a aplicação de um documento estabelecido unilateralmente e que o Conselho de Estado considera como um regulamento" (Cf. LAUBADËRE, André de, MODERNE, Franck e DEVOLVÉ, Pierre. Traité des Contrats Administratifs, Tomo I, LGDJ, Paris, 1983, p. 106). Ou seja, o contrato de concessão tem a capacidade de colocar o privado que a ele adere sob um estatuto, não apenas legal, como regulamentar.

29 OTERO, Paulo. Legalidade e Administração Pública - o sentido da vinculação administrativa à juridicidade, Ed. Almedina, Coimbra, 2003, pp. 522 e 523.

30 OTERO, Paulo. Legalidade e Administração Püblica - o sentido da vinculação administrativa à juridicidade, Ed. Almedina, Coimbra, 2003, pp. 524/5. 
Também EBERHARD SCHMIDT-ASSMANN observa que "o limite legal para os atos unilaterais não é necessariamente o limite dos contratos. Neste último caso, os limites se põem com mais liberdade. Todavia, em alguns casos concretos, uma reserva de lei institucional pode exigir que esses limites sejam fixados previamente por lei. Mas em regra geral a Administração não precisa de nenhuma base legal especial para celebrar contratos. Rege o princípio de que a configuração dos contratos é apenas dirigida pela lei." ${ }^{31}$

É esse, justamente, o caso das concessões petrolíferas, já que a Lei não as configura previamente de forma integral, e, muito pelo contrário, deixa larga margem de escolhas a serem efetuadas pelo órgão regulador, cujos poderes têm até mesmo sede constitucional (art. 177, $\S 2^{\circ}$, III, CF). Podemos afirmar que as previsões contratuais de direitos ou obrigaçōes ex novo para os concessionários é plenamente admissível, salvo se for incompatível com a Lei do Petróleo, suas regras e princípios.

\section{III - A função das boas práticas da indústria do petróleo}

Na definição das opções corretas e das interpretações razoáveis a serem procedidas pela Agência Nacional do Petróleo - ANP, as "boas práticas internacionais da indústria do petróleo" (art. 44, VI, Lei do Petróleo) possuem um papel primordial, já que é através delas que a ANP deve implementar o modelo de mercado e de atração de investimentos propugnado pela Emenda Constitucional $n^{\circ} 09 / 1995$, que flexibilizou o monopólio do petróleo, e pela Lei do Petróleo, que a regulamentou. ${ }^{32}$

A minuta do contrato de concessão da Sexta Rodada, ${ }^{33}$ seguindo o que já constava das rodadas anteriores, define (Cláusula 1.2.21) as "Melhores Práticas da Indústria do Petróleo" como "as práticas e procedimentos geralmente empregados na indústria de Petróleo em todo o mundo, por Operadores prudentes e diligentes, sob condições e circunstâncias semelhantes àquelas experimentadas relativamente a aspecto ou aspectos relevantes das Operações, visando principalmente a garantia de: (a) conservação de recursos petrolíferos e gaseíferos, que implica na utilização de métodos e processos adequados à maximização da recuperação de hidrocarbonetos de forma técnica e economicamente sustentável, com o correspondente controle do declínio de reservas, e à minimização das perdas na superfície; (b) segurança operacional, que impõe o emprego de métodos e processos que assegurem a segurança ocupacional e a prevenção de acidentes operacionais; (c) proteção ambiental, que

31 SCHMIDT-ASSMANN, Eberhard. La Teoría General del Derecho Administrativo como Siste$m a$, trad. Mariano Bacigalupo et alli), Ed. Marcial Pons, Barcelona, 2003, p. 327.

32 "Constitui (a Lei do Petróleo) um importante marco: demonstra que, no Brasil, a indústria do petróleo atingiu a maturidade e está sendo aberta para possibilitar novos investimentos e permitir uma interação equilibrada entre o Estado e a iniciativa privada" (Exposição de Motivos $n^{\circ} 25 / 96$, do Ministério das Minas e Energia, que encaminhou à Presidência da República o respectivo Anteprojeto de Lei).

33 Constante de http://www.brasil-rounds.gov.br/round6/contrato/Contrato_R6_minuta.pdf, acessado em 13/4/04. 
determina a adoção de métodos e processos que minimizem o impacto das Operações no meio ambiente".

Dessa definição, extraem-se, basicamente, os seguintes elementos: a prática deve ser encontradiça internacionalmente, há de ser cautelosa e deve ser racional do ponto de vista da preservação dos recursos, e segura e respeitosa do meio ambiente.

Quando se afirma que as práticas devam ser internacionais não se está a dizer que devam ser absolutamente comuns a todas as regiões do mundo em que haja exploração de petróleo, já que são muitas as peculiaridades e diferenças existentes entre elas, sendo plenamente satisfatório, e de certa forma até mais eficaz, dada a maior especificidade e afinidade, que a prática internacional seja comum a regiões cujas características geológicas e econômicas sejam semelhantes às encontradas no Brasil. $^{34}$

Essas práticas, expõe MARIA D'ASSUNÇÃo COSTA MENEZELLO, "são amplamente conhecidas e decorrem das recentes normalizações internacionais ou de usos consagrados, com qualidade e eficiência para todos os envolvidos, proporcionando uma evolução constante das técnicas e dos conhecimentos científicos" ${ }^{35}$ MARILDA ROSADO DE SÁ RIBEIRO destaca que "as obrigações conjuntas na área do petróleo foram conduzidas de acordo com os princípios gerais das leis de contenancy, relacionadas às sociedades de mineração à lei dos contratos". ${ }^{36}$

Hoje, ressalta a Ilustre Professora da Universidade do Estado do Rio de Janeiro - UERJ, ${ }^{37}$ estas práticas já se encontram consolidadas no modelo de contrato de parceria entre empresas exploradoras de petróleo (JOA - joint operating agreements) elaborado pelo International Energy Committee da American Corporate Counsel Association (ACCA) e pela Association of International Petroleum Negotiators (AIPN), constitutivo de um verdadeiro código normalizador das condutas no setor. $^{38}$

A minuta-padrão é acolhida nos países com as culturas jurídicas das mais diversas, já que, "embora tudo leve a crer que os modelos iniciais dos JOAs internacionais foram reproduzidos de textos da tradição anglo-saxã, a sua utilização por grupos de empresas de nacionalidades distintas, e com foco de preocupações e

34 "Ao Direito compete promover a igualaçāo dos iguais e o tratamento diversificado apenas daqueles que se diversifiquem segundo critérios de justiça racionalmente postos e suficientemente motivados. (...) Em verdade, o que se pretende é que (...) não crie desigualdades entre pessoas em situação jurídica que permita a igualação e seja este o enfoque a ser relevado para o desate justo da questão normada (...)" (ROCHA. Carmem Lúcia Antunes da. O Princípio Constitucional da lgualdade, Ed. Lê, belo Horizonte, 1990, p. 39).

35 MENEZELlo Maria D'assunção Costa. Comentários à Lei do Petróleo, Ed. ATLAS São Paulo, 2000, p. 137.

36 RIBEIRO, Marilda Rosado de Sá. Direito do Petróleo: as joint ventures na Indístria:do Petróleo, 2 edição, Ed. Renovar, Rio de Janeiro, 2003, p. 239.

37 RIBEIRO, Marilda Rosado de Sá. Direito do Petróleo: as joint ventures na Indústria do Petróleo, 2a edição. Ed. Renovar. Rio de Janeiro, 2003, p. 202 e seguintes.

38 RIBEIRO, Marilda Rosado de Sá. Direito do Petróleo: as joint ventures na Indústria do Petróleo, $2^{\mathrm{a}}$ edição, Ed. Renovar, Rio de Janeiro, 2003, p. 202 e seguintes. 
práticas operacionais e administrativas distintas, para operação em países de diversos continentes, gerou uma variedade de abordagens e soluções (...). A necessidade de tornar ágil a fase preparatória, e até o processo negocial, fez crescer a preferência pela uniformização. (...) Independentemente do grau de aceitação da minuta elaborada pela ACCA e a AIPN teve como base universal para negociações, ela foi o resultado de um trabalho sério, cujo propósito consistiu em dar o devido dimensionamento a diferenças entre opções nas diversas cláusulas do JOA, bem como avaliar seu valor econômico e seu impacto no restante do contrato. Com sua adoção, é possível superar o empirismo e o casuísmo que, por vezes, podem presidir a estratégia de aceitação e negociação de alterações de cláusulas. Por outro lado, as negociações podem incluir e beneficiar-se, no seu preparo e estratégia, de um material que consolida uma experiência analítica de peso dos negociadores e advogados de diferentes empresas de petróleo e escritórios de advocacia do ramo, e conta, no seu plano de fundo, com um acervo comparativo razoável a partir da vivência e atualização dos próprios partícipes. Para as empresas, o patrocínio da AIPN tem se revelado um investimento de bom retorno, quando se compara o número de horas anteriormente despendido com negociações ora encurtadas pelos textos básicos de ampla aceitação". ${ }^{39}$

Ora, é óbvio que à Agência Nacional do Petróleo - ANP não cabe apenas observar as cláusulas constantes da minuta-padrão da ACCA/AIPN, possuindo, outrossim, um juízo avaliativo crítico para ponderá-la com outras práticas da indústria e para verificar se estão todas elas de acordo com a Lei do Petróleo.

Não poderá, reversamente, ex vi do art. 44, VI, da Lei do Petróleo, refutar a incorporação ao contrato de concessão de cláusulas que reflitam as "boas práticas internacionais da indústria do petróleo" tal como acima expostas, salvo se não houver, com base em qualquer juizo hermenêutico razoável de outros dispositivos da Lei do Petróleo e da Constituição Federal, espaço deixado para a Agência incorporá-las, seja na integração (complementação da Lei em pontos que não foram por ela especificamente tratados), seja na interpretação da Lei. Em outras palavras, as "boas práticas" só podem deixar de ser acolhidas nas concessões se forem contrárias à lei ou à Constituição.

$\mathrm{Na}$ verdade, sendo o contrato de concessão petrolífera um "acordo de desenvolvimento econômico" ${ }^{40}$, as suas cláusulas devem ser colocadas dentro desse objetivo desenvolvimentista.

Como já havíamos afirmado em outra oportunidade, ${ }^{41}$ hoje se tem a consciência de que, quanto mais o Direito conhecer o campo a ser regulado, mais chances terá

39 RIBEIRO, Marilda Rosado de Sá. Direito do Petróleo: as joint ventures na Indústria do Petróleo, 2 edição, Ed. Renovar, Rio de Janeiro, 2003, pp. 202 e 206.

40 Cf. BUCHEB, José Alberto. A Arbitragem Internacional nos Contratos da Indústria do Petróleo, Lumen Juris, Rio de Janeiro, 2002, p. 11.

41 ARAGĀO, Alexandre Santos de. Ensajo de uma visão Autopoiética do Direito Administrativo, in Revista de Direito Público da Economia - RDPE, vol. 04. 
de propiciar uma regulação eficiente e dotada de maior efetividade. Se a assertiva é correta de maneira geral, deve ser reforçada em relação à regulação da economia.

A economia, potencializando um fenômeno de dinamismo, de relativa imprevisibilidade e de tendências autonomizadoras, que sempre foram da sua própria essência, tem, nessas últimas décadas, de globalização e de internacionalização das fases da cadeia produtiva, feito com o que o Direito incorpore cada vez mais lógicas e códigos das atividades a serem reguladas.

Merece uma especial atenção, assim, a tecnicidade do marco regulatório das atividades petrolíferas, que desde o seu surgimento nos Estados Unidos foram se desenvolvendo de maneira empírica, que hoje poderia ser chamada de auto-regulada. Isso se refletiu na encampação de exigências técnicas e econômicas da Indústria por parte do marco regulatório estatal, "tecnicidade relacionada com a especificidade das atividades a serem disciplinadas, que necessitam de normas pontuais, remetidas à autonomia de órgãos técnicos, organizando setores específicos e assegurando a flexibilidade e a permeabilidade às exigências da sociedade econômica" 42

A adoção, encampação e respeito às "boas práticas internacionais da indústria do petróleo" nos contratos de concessão da ANP, inclusive com vistas à "racionalização da produção" (art. 44, VI, Lei do Petróleo), constitui o meio por excelência eleito pela Lei para melhor atingir os seus objetivos fixados no art. $1^{\circ}$ (proteção do interesse nacional, do desenvolvimento, do meio ambiente, dos consumidores, garantir o fornecimento nacional dos derivados do petróleo, atração de investimentos, ampliar a competitividade do País no mercado internacional, promover a concorrência, etc.).

Em relação aos preceitos legais que, a exemplo do art. 44, VI, da Lei do Petróleo, encampam práticas disseminadas entre os agentes de determinado setor econômico, são essenciais os ensinamentos de MARC TARRÉS VIVES ${ }^{43}$, segundo os quais "a insuficiência do instrumental administrativo tradicional deve ser complementada mediante a implementação na regulação administrativa de fórmulas auto-regulativas que, considerando a sua legitimidade na consecução de interesses privados individuais ou coletivos, permitem a satisfação de finalidades públicas. (...) Há uma vontade de usar, como instrumento diretivo, os compromissos, meios e conhecimentos que esses agentes possuem com a finalidade de lograr a realização de fins públicos. Em outras palavras, a auto-regulação se integra na regulação. (...) A regulamentação tem, em boa medida, deixado de conter complexas prescrições técnicas - que em sua literalidade e ampla extensão consumiam páginas de Diário Oficial - para limitar-se a declarar uma cláusulas gerais, que encontram a sua concreção a partir da remissão por elas realizada, (...) o que não é nenhuma novidade".

42 COCOZZA, Francesco. Profili di Diritto Costituzionale applicato all'Edconomia, Volume I (Incidenza dei Rapporti Economici sull 'Organizzazione del Potere Politico e sul Sistema delle Fonti del Diritto), G. Giappichelli Editore, Torino, 1999, p. 171.

43 VIVES, Marc Tarrés. Normas Técnicas y Ordenamiento Juridico, Ed. Tirant lo Blanch, Valencia, 2003, pp. 172 e 253. 
Mais adiante leciona que "o uso desse tipo de expressões (como a de "boas práticas da indústria do petróleo") por parte das normas jurídicas demonstra uma renúncia explícita do Legislador à elaboração detalhada de regulamentações técnicas que, na verdade, poderiam tornar-se obsoletas pouco tampo após a sua publicação, devendo-se reconhecer também que a utilização de conceitos jurídicos indeterminados com este objetivo constitui uma técnica legislativa amplamente adotada em áreas bem diversas, como a dos produtos industriais, das tecnologias da informação, meio ambiente, economia, etc." 44

Tratando dos códigos de "boas práticas" dos agentes econômicos de determinado setor, o autor afirma que elas "condensam critérios normas e valores que são formulados e seguidos no marco de uma atividade empresarial ou profissional. Adverte M. DARNACULLETA que 'os códigos (de boas práticas) podem conter, não só uma relação de valores, como também uma descrição das condutas consideradas de acordo com tais valores e as condutas reprováveis por serem contrárias aos mesmos"." 45

Assim, se determinada cláusula constitui uma "boa prática internacional da indústria do petróleo" (art. 44, VI, Lei do Petróleo) e contribui para a atração de investimentos para o País, com benefícios para os consumidores e para a concorrência, tornando a licitação mais atraente, com o conseqüente aumento dos valores de outorga a serem ofertados, só poderia ser obstada se houver razões de interesse público fortes o suficiente, e inexistirem outros meios menos onerosos para os parceiros privados para atender a essas específicas razões de interesse público.

É o Princípio Constitucional da Eficiência (art. 37, caput, CF) que deve iluminar a aplicação das leis, para que ela não leve a uma consecução ineficiente ou menos eficiente dos objetivos legais primários daquele ordenamento setorial. As normas "passam a ter o seu critério de validade aferido não apenas em virtude da higidez do seu procedimento criador, como da sua aptidão para atender aos objetivos da política pública, além da sua capacidade de resolver os males que esta pretende combater". ${ }^{46}$

Também pelo Princípio da Proporcionalidade, em seus elementos "adequação" e "necessidade", não se poderia impor a adoção de meio (normalmente uma interpretação) inadequado ou desnecessariamente oneroso ao atingimento das finalidades legais. ${ }^{47}$

44 VIVES, Marc Tarrés. Normas Técnicas y Ordenamiento Juridico, Ed. Tirant lo Blanch, Valencia, 2003, pp. 274/5.

45 VIVES, Marc Tarrés. Normas Técnicas y Ordenamiento Juridico, Ed. Tirant lo Blanch, Valencia, 2003, p. 237.

46 MORAND, Charles-Albert. Le Droit Néo-Moderne des Politiques Publiques, LGDJ, Paris, 1999, p. 95.

47 "Em função do objetivo (do fim, da vontade do Legislador) a ser realizado (também com a participação dos privados: essencial também para uma melhor identificação dos interesses envolvidos), a Administração deve construir uma decisão concreta e operativa, que conserve o mais possível os bens pessoais não incompatíveis com o bem-direito de relevância pública e que satisfaça o maior número de interesses possível. satisfazendo, desta forma, o maior número de direitos 
O modelo das normas jurídicas "hipótese de incidência sançâo" continua a existir, mas não é mais o único nem o mais importante, ${ }^{48}$ a ele tendo se somado o das normas jurídicas estruturadas pelo esquema "finalidades meios de alcance destas finalidades". ${ }^{49}$ In casu temos as "boas práticas" como o meio geraimente mais eficiente e menos oneroso, para a União e para particulares, de realização dos objetivos da Lei do Petróleo. ${ }^{50}$

NORBERTO BOBBIO, em preciosa passagem, observa que "se trata da passagem de um controle social fundado principalmente sobre normas providas de sanções ('Se fizer, ou não fizer, $x$, lhe será imputada a consequiência y'), ao controle social confiado cada vez mais a normas técnicas cuja força deriva da relação meiofim, ou seja, do fato de que a realização ou não de certa ação não permite alcançar o fim desejado ou imposto". 51

Assim, transpondo a lição de BOBBIO para o Direito Público do Petróleo, podemos concluir afirmando que, salvo demonstração em contrário, serão as boas práticas da indústria do petróleo que, como meio em princípio mais idôneo para alcançar o principal objetivo da Lei do Petróleo, que é justamente o desenvolvimento dessa indústria em nosso País, que legitimarão as medidas regulatórias (cláusulas contratuais, resoluções, etc.) a serem esp ecificamente adotadas ou refutadas pela Agência Nacional do Petróleo - ANP.

fundamentais" (IANNOTTA, Lucio. Princípio di Legalità e Amministrazione di Risultato, in Amministrazione e Legalità - Fonti Normativi e Ordinamenti (Atti del Comvegno, Macerata, 21 e 22 maggio 1999), Giuffrè Editore, Milano, 2000, pp. 45).

48 MORAND. Charles-Albert. Le Droit Néo-Moderne des Politiques Publiques, LGDJ. Paris. 1999, pp. 101/2.

49 Revelando a aplicação destas mudanças da Teoria Geral do Direito ao Direito Administrativo, EDUARDO GARCÍA DE ENTERRÍA afïma que a noção meramente subsuntiva ou "declaratória" do direito "é própria dos sistemas jurídicos private law oriented, ordenados pelo Direito Privado (próprio de uma época pré-industrial e agrícola), que permite que se considere o direito como um sistema fechado de conceitos, próprio de uma sociedade estática, mas que é inconciliável com a época atual de proliferação e predomínio do Direito Público, que exige que vejamos o Direito como um processo aberto em função de finalidades e objetivos a alcançar; o Direito Público — acresce - é um processo sem fim, uma indefinida sucessão de soluçōes parciais a questōes políticas" (ENTERRÍA. Eduardo García de. La Constitución como Norma y el Tribunal Constitucional. Ed. Civitas, Madrid, pp. 181/2).

50 " A interpretação da norma é obviamente finalizada à aplicação a uma realidade delimitada e circunscrita. Quem decide, sobretudo na fase de emissão da decisão, deve colher na norma, prioritariamente, os objetivos das leis, os fins, a vontade do legislador. Os bens que a norma quis proteger e, portanto, o resultado que quis alcançar; devendo-se distinguir. portanto, no interior da norma, aquilo que é verdadeiramente finalístico (bens a serem protegidos, males a serem evitados) dos outros componentes (meios, instrumentos, formas) correspondentes aos vários planos da realidade reproduzida e sintetizada pela norma" (IANNOTTA. Lucio. Princípio di Legalità e Amministrazione di Risultato, in Amministrazione e Legalità - Fonti Normativi e Ordinamenti (Atti del Convegno. Macerata, 21 e 22 maggio 1999), Giuffrè Editore, Milano, 2000, pp. 44/5).

51 BOBBIO, Norberto. Dalta Strutura alla Funzione: nuovi studi di teoria del diritto, Edizioni di Comunità, Milano, 1977, p. 54. 